\title{
SENSORS ARRAY FOR MONITORING AND AUTOMATION OF THE ELECTROCHEMICAL RECOVERY OF METALS FROM WASTE PRINTED CIRCUIT BOARDS
}

\author{
SORIN-AUREL DORNEANU, b, c, ENIKO COVACI ${ }^{\mathrm{a}, \mathrm{b}}$, \\ FLORICA IMRE-LUCACI ${ }^{\mathrm{b}}$, GRAZIELLA LIANA TURDEAN ${ }^{\mathrm{a}, \mathrm{c}, \text { * }}$
}

\begin{abstract}
Nowadays there is increasing interest in using various electrochemical methods as alternative to the energy consuming physico mechanical, hydrometallurgical and pyrometallurgical techniques for metals recovery from waste printed circuit boards (WPCBs). Thus, cyclic voltammetry (CV) and cyclic square-wave voltammetry (CSWV) methods were used for studying the electrochemistry of some metals ( $\mathrm{Cu}, \mathrm{Sn}, \mathrm{Pb}, \mathrm{Fe}, \mathrm{Zn}$ ) on glassy carbon electrode from synthetic leaching solutions containing known concentrations of metallic ions and in real solution obtained from dissolving 10 WPCBs. A good linear correlation was obtained between the parameters evaluated by ICP-OES and cyclic voltammetry. The influence of $\mathrm{pH}$ and oxidation/reduction potential (ORP) on the corrosion rate of the mentioned metals was studied gravimetrically. Based on the obtained results, a complex sensors array (amperometric, $\mathrm{pH}$, temperature and ORP) was proposed to assure the accurate monitoring and control of the electrochemical process for metals recovery from WPCBs.
\end{abstract}

Keywords: waste printed circuit boards, metals recovery, sensor array, potentiometric and voltammetric sensors

a Babeş-Bolyai University, Faculty of Chemistry and Chemical Engineering, 11 Arany Janos St., RO-400028, Cluj-Napoca, Romania

b Interdisciplinary Research Institute on Bio-Nano-Sciences, 42 Treboniu Laurian St., RO-400271, Cluj-Napoca, Romania

c Research Center of Electrochemistry and Nonconventional Materials, "Babes-Bolyai" University, 11, Arany Janos St., RO-400028, Cluj-Napoca, Romania

*Corresponding author: gturdean@chem.ubbcluj.ro 


\section{INTRODUCTION}

The continuous development and the huge production of electrical and electronic equipment leads to generate great quantities of waste printed circuit boards (WPCBs). Those boards contain an important concentration of heavy metals (like $\mathrm{Cu}, \mathrm{Sn}, \mathrm{Pb}, \mathrm{Fe}, \mathrm{Zn}$ ) and low concentrations of precious and rare metals (Au, $\mathrm{Ag}, \mathrm{Ga}, \mathrm{In})$ [1-3]. During the leaching process, the metals from WPCBs are transferred into solution, from where metals could be removed and recovered. Due to the high quantities of WPCB and the complex content of the obtained leaching solution, the recovery of even a fraction of metals is becoming a difficult and increasingly important challenge.

Current recycling processes are pyro- [4] and hydro-metallurgical alone [5] or coupled with complementary processes like: electrodeposition, adsorption, ion exchange, extraction, precipitation, membrane separation, solvent extraction and biochemical treatment [6].

It was shown that from environmental and economic points of view, electrochemical recycling of metals from WPCBs have many advantages in comparison to other recovering methods mentioned above $[7,8]$. Thus, this technique (i) can operate continuously and yields a metallic form of the product with very high purity which is suitable for rapid reuse or resale and (ii) employs simple electric devices and requires minimal reagent consumption, without additional waste streams [9, 10]. The major challenges for the electrochemical recycling techniques are the increasing of the metals leaching speed and the selectivity improving of the metals electrodeposition of from WPCBs leaching solution by an accurate controlling of the electrochemical operating parameters. Our preliminary results [11] revealed that a model able to predict the behaviour of the chemical and electrochemical reactors and optimize the process parameters must take into consideration some factors. The most important from them are the potential and the concentration profiles at the cathode/electrolyte interface level for the conditions in which the migration and convective diffusion control to overall transport rates.

The aim of the present paper was to find simple and accurate analysis techniques able to evaluate the main process parameters that control the metals leaching rate from WPCBs and the metals selective electrodeposition from the leaching solutions. Consequently, a complex sensor arrays (amperometric, $\mathrm{pH}$, temperature and ORP) was designed for an accurate monitoring and control of the electrochemical process for metals recycling from WPCBs. 


\section{RESULTS AND DISCUSSION}

\section{Electrochemical behavior in synthetic solutions}

The cyclic voltammetry (CV) and cyclic square-wave voltammetry (CSWV) were used to evaluate the electrochemical behaviors of the most abundant metals in WPCBs. The measurements were performed using a glassy carbon (GC) working electrode, an $\mathrm{Ag} / \mathrm{AgCl} / \mathrm{KCl}$ sAt reference electrode (REF) and a $\mathrm{Pt}$ wire as counter electrode immersed in synthetic solution samples (SSSs) containing $2 \mathrm{M} \mathrm{KBr}$ and $0.5 \mathrm{M} \mathrm{HBr}$ and individual metallic ions (i.e., $\mathrm{Cu}^{2+}, \mathrm{Sn}^{2+}$, $\mathrm{Pb}^{2+}, \mathrm{Fe}^{2+}, \mathrm{Zn}^{2+}$ ) at different concentrations. As it can be seen in Figure $1 \mathrm{~A}$, the studied metallic ions are involved either in redox (peaks A1/C1) or in dissolution/ electrodeposition (peaks A2/C2) processes.
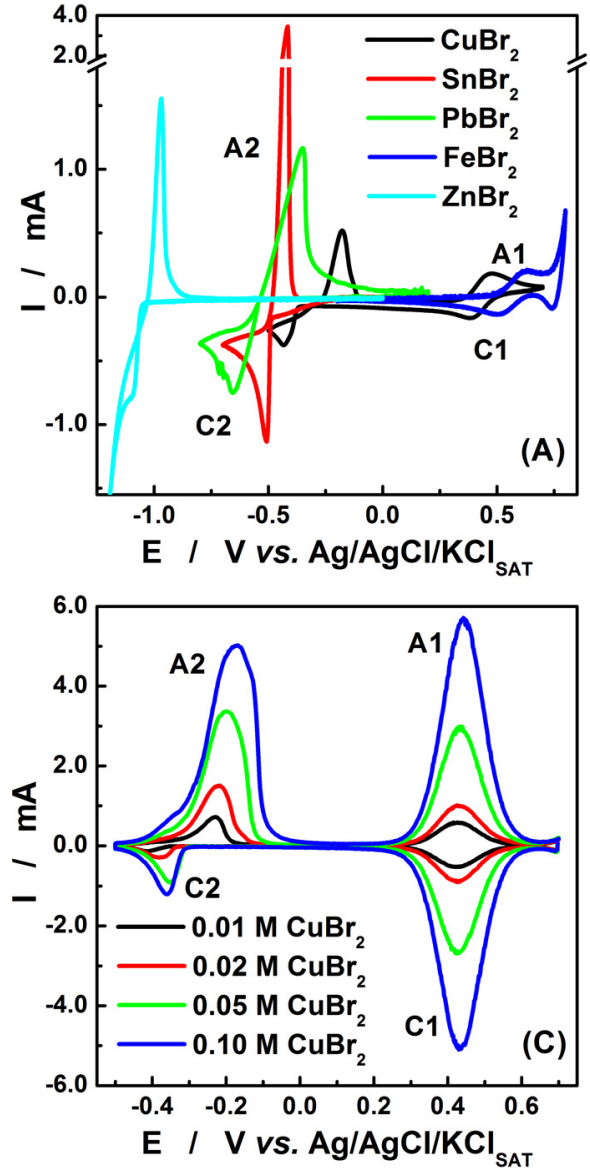

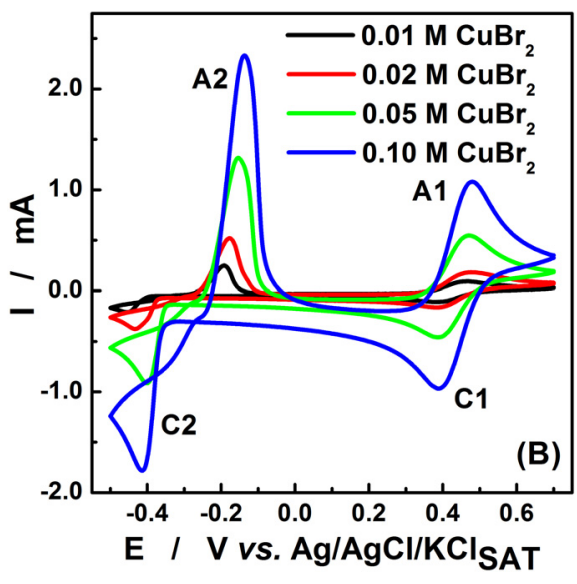

Figure 1. Voltammograms recorded by $\mathrm{CV}$ on $\mathrm{GC}$ electrode in $2 \mathrm{M} \mathrm{KBr}+0.5$ $\mathrm{M} \mathrm{HBr}+0.02 \mathrm{M} \mathrm{MeBr}_{2}$ (see inset) $(\mathbf{A})$. Voltammograms recorded by $\mathrm{CV}$ (B) and CSWV (C) on GC electrode in $2 \mathrm{M}$ $\mathrm{KBr}+0.5 \mathrm{M} \mathrm{HBr}+\mathrm{CuBr}_{2}$ of different concentrations (see inset) 
Accordingly to literature [12], for SSSs containing $2.5 \mathrm{M} \mathrm{Br}$, the majority of cuprous bromide species are $\mathrm{CuBr}_{3}{ }^{-2}, \mathrm{CuBr}_{2}{ }^{-}$and $\mathrm{Cu}_{3} \mathrm{Br}_{6}{ }^{-3}$ and of cupric bromide species are $\mathrm{CuBr}_{4}{ }^{-2}$ and $\mathrm{CuBr}_{3}{ }^{-}$, respectively. In these conditions, as it can be seen from Table 1, the values of the formal peak potential $\left(\mathrm{E}^{0}\right.$ 'calc $)$, calculated as the arithmetical mean of the anodic $\left(\mathrm{E}_{\mathrm{ap}}\right)$ and cathodic $\left(E_{c p}\right)$ peak potential values, are in good agreement with the theoretical values ( $\mathrm{E}^{0}$ 'theor), only minor negative shifts of -10 and $-28 \mathrm{mV}$ being observed for the $\mathrm{Fe}^{3+} / \mathrm{Fe}^{2+}$ and $\mathrm{Cu}^{2+} / \mathrm{Cu}^{+}$redox couples, respectively.

Table 1. Peak potential values recorded by $\mathrm{CV}$ on $\mathrm{GC}$ in $0.1 \mathrm{M} \mathrm{Cu}^{2+}$ and $\mathrm{Fe}^{3+}$ in SSSs and the corresponding formal and theoretical potentials

\begin{tabular}{|l|c|c|c|c|c|}
\hline Process & $\mathbf{E}_{\text {ap }}$ (A1) & $\mathbf{E}_{\text {cp }}$ (C1) & $\mathbf{E}^{0}{ }_{\text {calc }}$ & $\mathbf{E}^{{ }^{0}{ }^{\prime}{ }_{\text {theor }}{ }^{*}}$ & $\Delta \mathbf{E}$ \\
\hline $\mathrm{Cu}^{2+} / \mathrm{Cu}^{+}$ & $0.480 \mathrm{~V}$ & $0.390 \mathrm{~V}$ & $0.435 \mathrm{~V}$ & $0.463 \mathrm{~V}$ & $-0.028 \mathrm{~V}$ \\
\hline $\mathrm{Fe}^{3+} / \mathrm{Fe}^{2+}$ & $0.620 \mathrm{~V}$ & $0.510 \mathrm{~V}$ & $0.565 \mathrm{~V}$ & $0.575 \mathrm{~V}$ & $-0.010 \mathrm{~V}$ \\
\hline
\end{tabular}

${ }^{*} \mathrm{E}^{0}$ 'theor $(\mathrm{V} / \mathrm{REF})=\mathrm{E}^{0}$, $(\mathrm{V} / \mathrm{SHE}[12,13])-\mathrm{E}_{\mathrm{REF}}(=0.197 \mathrm{~V} / \mathrm{SHE})$

Even if in the tested solutions the $\mathrm{Fe}^{3+} / \mathrm{Fe}^{2+}$ and $\mathrm{Cu}^{2+} / \mathrm{Cu}^{+}$redox couples present a quasi-reversible behavior (the peak-to-peak separation, $\Delta E_{p}=E_{p a}-E_{p c}>100 \mathrm{mV}$ ), the amplitude of the corresponding peaks can be used to evaluate the concentration of the two species. The main processes corresponding to the A1/C 1 peaks are:

$$
\begin{aligned}
& \mathrm{Fe}^{2+}+\mathrm{e}^{-} \leftrightarrow \mathrm{Fe}^{3+} \\
& {\left[\mathrm{CuBr}_{4}\right]^{-2}+\mathrm{e}^{-} \leftrightarrow\left[\mathrm{CuBr}_{3}\right]^{-2}+\mathrm{Br}^{-}}
\end{aligned}
$$

and, for the $\mathrm{A} 2 / \mathrm{C} 2$ peaks, the next processes take place:

$$
\begin{aligned}
& \mathrm{Me}^{2+}+2 \mathrm{e}^{-} \leftrightarrow \mathrm{Me}^{0}, \quad \text { where: } \mathrm{Me}^{0}=\mathrm{Sn}, \mathrm{Pb}, \mathrm{Zn} \\
& {\left[\mathrm{CuBr}_{3}\right]^{-2}+\mathrm{e}^{-} \leftrightarrow \mathrm{Cu}^{0}+3 \mathrm{Br}}
\end{aligned}
$$

For all studied metallic ions, the voltamograms recorded by $\mathrm{CV}$ and CSWV measurements reveal strength dependence between the ions concentrations and peak current intensities for oxidation/reduction and dissolution/electrodeposition, this fact being exemplified for $\mathrm{Cu}$ in the Figures $1 \mathrm{~B}$ and $1 \mathrm{C}$. As expected, the CSWV is a more sensitive technique, showing higher peak current intensities like those obtained in CV, but peaks limitations appear for $\mathrm{Cu}$ concentrations greater than $50 \mathrm{mM}$.

Also, the peak potentials could be used for the identification of the metallic ions and the intensities of the corresponding peaks can be successfully used for the concentrations monitoring. For example, in Figure 2, the calibration curves, obtained by plotting the peak currents recorded by CV versus $\mathrm{MeBr}_{2}$ concentration, are presented for some metals. 


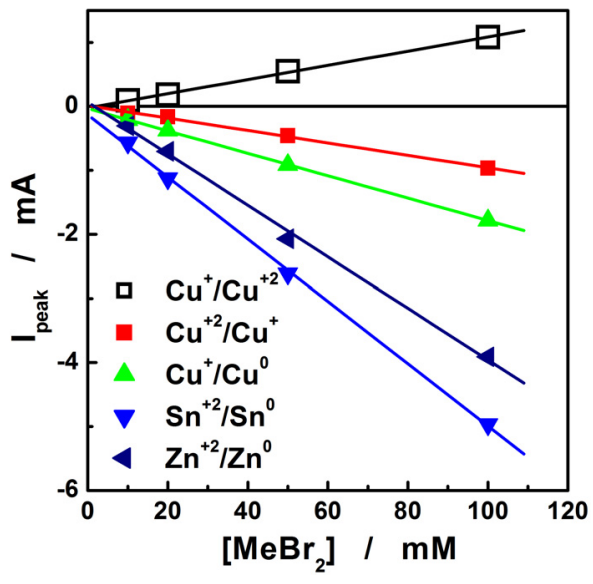

Figure 2. Examples of calibration curves resulted for electrodeposition $(\mathrm{C} 2)$, reduction $(\mathrm{C} 1)$, dissolution $(\mathrm{A} 2)$ and oxidation $(\mathrm{A} 1)$ peaks recorded by $\mathrm{CV}$ in $\mathrm{MeBr}_{2}$ solutions

The parameters of the linear dependencies between the peak current intensities recorded by $\mathrm{CV}$ and the metallic ions concentrations, presented in Table 2, reveal a very good correlations (proved by the high values of the correlation coefficient, R) and high sensibilities.

Table 2. Sensibilities and correlation coefficients for some calibration curves

\begin{tabular}{|c|c|c|c|}
\hline Metallic ion & Peak process & Sensibility $(\boldsymbol{\mu} \mathbf{A} / \mathbf{m M})$ & $\mathbf{R} / \mathbf{n o}$ points \\
\hline \multirow{2}{*}{$\mathbf{C u}^{2+}$} & A1 & $11.1 \pm 0.2$ & $0.9995 / 4$ \\
\cline { 2 - 4 } & C1 & $9.7 \pm 0.4$ & $0.9987 / 4$ \\
\hline $\mathbf{C u}^{+}$ & C2 & $17.5 \pm 0.1$ & $0.9999 / 4$ \\
\hline $\mathbf{S n}^{2+}$ & C2 & $48.6 \pm 0.8$ & $0.9997 / 4$ \\
\hline $\mathbf{P b}^{2+}$ & C2 & $43.0 \pm 1.4$ & $0.9984 / 4$ \\
\hline \multirow{2}{*}{$\mathbf{F e}^{2+}$} & A1 & $9.9 \pm 0.3$ & $0.9994 / 4$ \\
\hline \multirow{2}{*}{$\mathbf{Z n}^{2+}$} & C1 & $6.2 \pm 0.3$ & $0.9981 / 4$ \\
\cline { 2 - 4 } & A2 & $76.7 \pm 5.1$ & $0.9956 / 4$ \\
\cline { 2 - 4 } & C2 & $40.2 \pm 1.4$ & $0.9988 / 4$ \\
\hline
\end{tabular}

The highest sensibilities are recorded by $\mathrm{CV}$ in the case of the Sn, $\mathrm{Pb}$ and $\mathrm{Zn}$ electrodeposition, suggesting an easier electrocrystallization of these metals on the GC surface.

\section{Electrochemical measurements in real sample solutions}

Our previous results [14] indicate that, depending on the type of studied WPCBs, the concentrations of the studied metals in the obtained leaching solutions present a significant dispersion, the maximum ([Me $\left.]_{\mathrm{MAX}}\right)$, minimum $\left([\mathrm{Me}]_{\text {MIN }}\right)$ and average ([Me $]_{\text {MEAN }}$ ) concentration values and the corresponding standard deviation (SD) being presented in Table 3. 
SORIN-AUREL DORNEANU, ENIKO COVACI, FLORICA IMRE-LUCACI, GRAZIELLA LIANA TURDEAN

Table 3. Concentration ranges of the more abundant metals in the obtained leaching solutions from 10 WPCBs samples

\begin{tabular}{|l|c|c|c|c|c|c|c|}
\hline Metal & $\mathbf{C u}$ & $\mathbf{S n}$ & $\mathbf{Z n}$ & $\mathbf{F e}$ & $\mathbf{P b}$ & $\mathbf{A l}$ & $\mathbf{N i}$ \\
\hline$[\text { Me }]_{\text {MAx }}(\mathbf{m M})$ & 598 & 85 & 150 & 145 & 47 & 51 & 18 \\
\hline$[\text { Me }]_{\text {MIN }}(\mathbf{m M})$ & 343 & 53 & 34 & 34 & 0.2 & 9 & 10 \\
\hline$[\text { Me }]_{\text {MEAN }}(\mathbf{m M})$ & 461 & 71 & 111 & 81 & 26 & 27 & 13 \\
\hline SD (mM) & 70 & 12 & 37 & 32 & 15 & 14 & 3 \\
\hline
\end{tabular}

As it can seen from Table 3, the concentration ranges for $\mathrm{Cu}, \mathrm{Zn}, \mathrm{Fe}$ and $\mathrm{Pb}$ in the real sample solution (RSS) exceed the domains studied by $\mathrm{CV}$ and CSWV in SSSs. Moreover, due to the complex composition and the high metals ions concentrations in the undiluted RSSs, the peaks corresponding to the electrodeposition/dissolution (C2/A2) and/or oxidation/reduction (A1/C1) processes, evidenced either by CV or CSWV, are obviously limited and distorted. As a consequence, in order to obtain adequate analytical signals, for all further electrochemical measurements, the RSSs were diluted 10 times using $2 \mathrm{M}$ $\mathrm{KBr}+0.5 \mathrm{M} \mathrm{HBr}$ solution.

In these conditions, CV and CSWV become fast and inexpensive methods to evaluate qualitatively and semi-quantitatively the composition of the leaching solutions. As exemplified in Figure 3.A, the presence of $\mathrm{Pb}^{2+}$ in a RSSs is evidenced in CV by the apparition of a peak pair placed at $\mathrm{E}_{\mathrm{Pb} 2+/ \mathrm{Pb}}=$ $-0.565 \mathrm{~V} / \mathrm{REF}$ and $\mathrm{E}_{\mathrm{Pb} / \mathrm{Pb} 2+}=-0.480 \mathrm{~V} / \mathrm{REF}$. Contrarily, for RSSs resulting from WPCBs released after 2006, when EU RoHS directive [15] took effect, the corresponding $\mathrm{Pb}$ electrodeposition and dissolution peaks do not appear (Figure 3A, dashed red line).
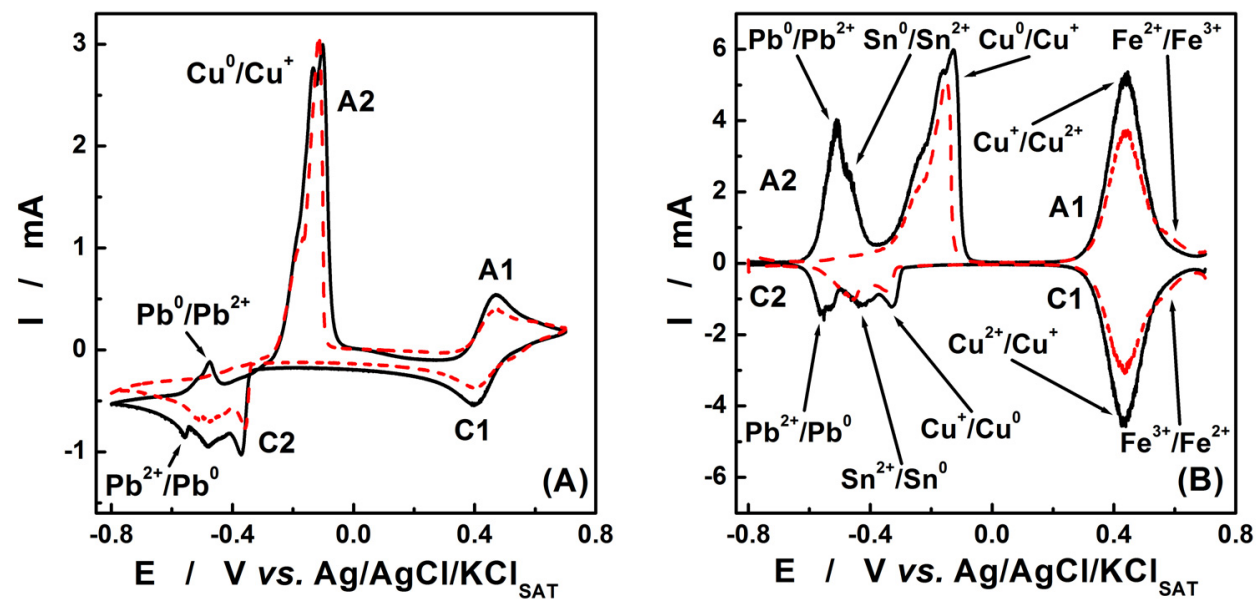

Figure 3. $C V(A)$ and CSWV (B) on GC electrode in 1/10 diluted RSSs containing $\mathrm{Pb}^{2+}$ (solid black line) and without $\mathrm{Pb}^{2+}$ (dashed red line) 
More interestingly, comparing Figures $1 \mathrm{~A}$ and $3 \mathrm{~A}$, we observed that the high amount of $\mathrm{Cu}$ present in the RSSs induce a considerable attenuation of the $\mathrm{Sn}$ and $\mathrm{Pb}$ metals dissolution peaks and a significant distortion of the $\mathrm{Cu}$ dissolution peak, suggesting the formation of the $\mathrm{Cu}-\mathrm{Sn}[16]$ and $\mathrm{Cu}-\mathrm{Sn}$ $\mathrm{Pb}[17]$ alloys during the electrodeposition step.

From another point of view, a higher Fe concentration in the sample containing $\mathrm{Pb}^{2+}$ determines the apparition of the second pair of peaks (of $\mathrm{A} 1 / \mathrm{C} 1$ type), associated with the $\mathrm{Fe}^{3+} / \mathrm{Fe}^{2+}$ redox couple.

As indicated in Figure 3B, all the previous mentioned phenomenon become more evident during the CSWV measurements, better peaks separation and higher amplitudes being recorded.

\section{Correlations of metallic ion concentrations evaluated by ICP-AES and electrochemical methods in real sample solutions}

Being an extremely complex matrix, the RSSs obtained by leaching a number of 10 WPCBs were analysed by ICP-AES standardized method. The correlation of the $\mathrm{Cu}^{2+}$ concentrations obtained by ICP-AES with those estimated based on CV data recorded in 10 times diluted RSSs is presented in Figure 4.

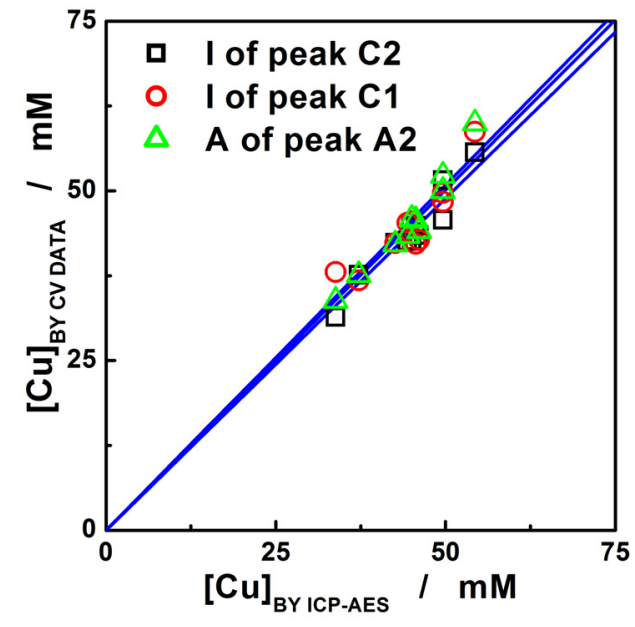

Figure 4. Correlation between $\mathrm{Cu}^{2+}$ concentrations obtained by ICP-AES and evaluated from CV data using the electrodeposition $\mathrm{C} 2$ peaks intensity $(\boldsymbol{\square})$, the reduction $\mathrm{C} 1$ peaks intensity $(\mathrm{O})$, and the area of the dissolution $\mathrm{A} 2$ peaks $(\triangle)(10$ times diluted RSSs $)$

Three CV data sets (i.e., the intensities of the electrodeposition (C2) and reduction (C1) peaks and the area of the dissolution (A2) peaks) were exemplified. From Figure 4 it can be seen that the concentrations of $\mathrm{Cu}^{2+}$ obtained by the two methods are in good agreement, the statistical parameters of the linear correlations being summarized in Table 4. 
Table 4. Statistical parameters for the linear correlations between the $\mathrm{Cu}^{2+}$ concentration obtained by ICP-AES and evaluated from CV data

\begin{tabular}{|c|c|c|c|c|}
\hline Method & Slope $(\mathbf{m M} / \mathbf{m M})$ & $\mathbf{R}$ & SD & $\mathbf{n}$ \\
\hline C2 peak height & $0.979 \pm 0.013$ & 0.9608 & 1.939 & 10 \\
\hline C1 peak height & $1.003 \pm 0.019$ & 0.9088 & 2.642 & 10 \\
\hline A2 peak area & $1.017 \pm 0.015$ & 0.9706 & 2.085 & 10 \\
\hline
\end{tabular}

As seen from the data presented in Table 4, the slopes of the linear correlations are very close to 1 (between 0.979 and 1.017), with correlation coefficients (R) higher than $90 \%$ and standard deviations (SD) not greater than 2.64 .

Similar correlations could be obtained using experimental data from CSWV (results not shown). It is important to note that, in the investigated potential range, the $\mathrm{Fe}$ electrodeposition/dissolution processes cannot be observed, but the Fe ions concentration can be evaluated based on A1/C1 peak pairs, subtracting the $\mathrm{Cu}$ signal. In this purpose, a dedicated algorithm was preliminarily tested with very promising results.

An enhancement of the data accuracy obtained by electrochemical methods (CV and CSWV) can be achieved by restricting the potential scan range, optimizing other experimental parameters (like the scan rate and/or the controlled electrolyte flow), and by recording new calibrations curves in mixed SSSs metals solutions similar to the RSSs.

\section{Influence of $\mathrm{pH}$ and oxidation-reduction-potential on the metals leaching rates}

It is well known that the $\mathrm{pH}$ and oxidation-reduction-potential (ORP) of the leaching solution influence significantly the rate of metals dissolution from WPCBs. In this context, Figure 5 presents the evolutions of $\mathrm{pH}, \mathrm{ORP}$ and corrosion rate $(\mathrm{CR})$ during the chemical leaching of different pure metallic samples of $\mathrm{Fe}, \mathrm{Sn}, \mathrm{Cu}$ and $\mathrm{Zn}$. As seen, for the tested metals, the dissolution processes are accompanied by the $\mathrm{pH}$ increase, simultaneously with the decrease of the OPR and CR.

Consequently, the track of the above parameters, using $\mathrm{pH}$ and ORP sensors and dedicated galvanic insulated electrometers, is essential for an adequate control and monitoring of the metals leaching process. Due to the high salinity and acidity, the leaching solutions conductivity is indistinctly affected by the dissolved metals concentrations, making irrelevant their monitoring. 


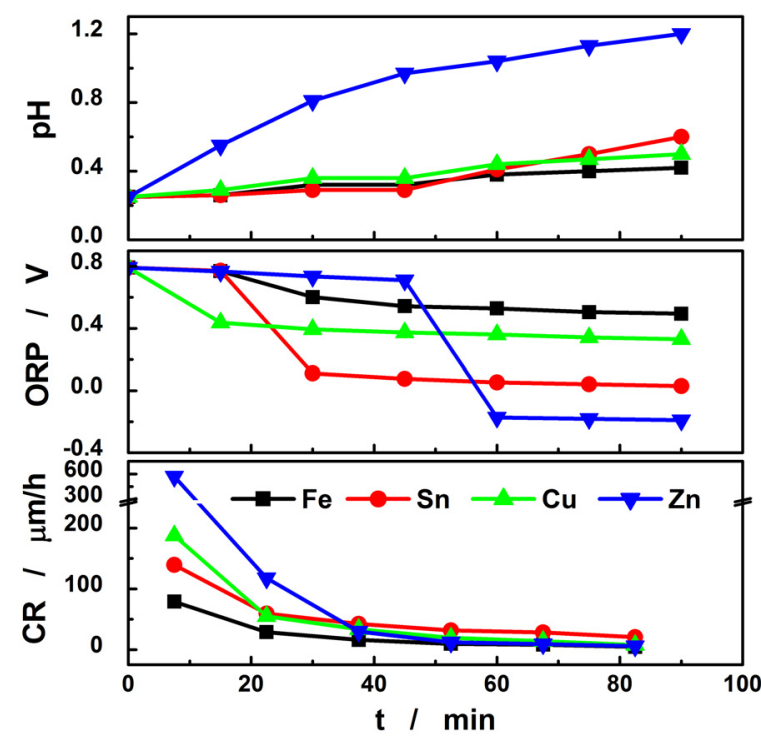

Figure 5. Evolution of $\mathrm{pH}$, OPR and corrosion rate values measured in $100 \mathrm{~mL}$ of leaching solution containing $2 \mathrm{M} \mathrm{KBr}+0.5 \mathrm{M} \mathrm{HBr}+0.1 \mathrm{M}$ $\mathrm{Br}_{2}$ for $8 \mathrm{~cm}^{2}$ samples of pure $\mathrm{Fe}(\boldsymbol{\square}), \mathrm{Sn}(\bullet), \mathrm{Cu}(\boldsymbol{\Delta}), \mathrm{Zn}$ $(\nabla)$; stirring rate: $480 \mathrm{rpm}$.

\section{CONCLUSIONS}

In order to efficiently monitor and control the process of electrochemical metals recovery from waste printed circuit boards, a complex sensors system, based on $\mathrm{pH}, \mathrm{OPR}$, temperature and voltammetric sensors, was designed and the included components were successfully tested in synthetic and real samples using dedicated LabView applications.

The simple and inexpensive voltammetric sensors, exploited by cyclic voltammetry and/or cyclic square wave voltammetry, allow the evaluation of the dissolved metals concentrations $(\mathrm{Cu}, \mathrm{Sn}, \mathrm{Pb}, \mathrm{Fe}, \mathrm{Zn})$ with satisfactory accuracy, eliminating the use of complex and expensive traditional analytical equipments and advanced dilutions.

The electric signals delivered by the proposed sensors allow their integration in a complex computerized and/or autonomous control system, simplifying the metals recovery process management and increasing its efficiency. 
SORIN-AUREL DORNEANU, ENIKO COVACI, FLORICA IMRE-LUCACI, GRAZIELLA LIANA TURDEAN

\section{EXPERIMENTAL SECTION}

\section{Chemicals}

Reagents as: $\mathrm{KBr}, \mathrm{HBr}, \mathrm{CuBr}_{2}, \mathrm{SnBr}_{2}, \mathrm{PbBr}_{2}, \mathrm{FeBr}_{2}$ and $\mathrm{ZnBr}_{2}$ are purchased by Fluka and Sigma-Aldrich.

Synthetic samples solutions are prepared by solving appropriate quantities of $\mathrm{CuBr}_{2}, \mathrm{Sn} \mathrm{Br}, \mathrm{Pb} \mathrm{Br}_{2}, \mathrm{Fe} \mathrm{Br}_{2}$ and $\mathrm{Zn} \mathrm{Br}_{2}$ in $2 \mathrm{M} \mathrm{KBr}+0.5 \mathrm{M}$ $\mathrm{HBr}$ solution.

Real samples solutions are obtained by leaching the metals from 10 PC motherboards (released between 1998 and 2008), in $2.2 \mathrm{~L}$ of $2 \mathrm{M} \mathrm{KBr}+$ $0.5 \mathrm{M} \mathrm{HBr}+1 \mathrm{M} \mathrm{Br}_{2}$ solutions [14].

\section{Experimental methods}

Cyclic voltammetry and cyclic square wave voltammetry were performed using a computer-controlled multi-channel potentiostat (DXC240, Datronix Computer, România) using dedicated LabView applications. The electrochemical cell was equipped with glassy carbon (GC) disc $(\phi=3 \mathrm{~mm})$ as working electrode, a $\mathrm{Ag} / \mathrm{AgCl} / \mathrm{KCl}_{\text {sat }}$ as reference electrode and a Pt wire $(\phi=0.5$ $\mathrm{mm}, \mathrm{L}=10 \mathrm{~cm}$ ) as counter electrode. For all the CV measurements, a scan rate of $50 \mathrm{mV} / \mathrm{s}$ was used. The CSWV measurements were performed at a frequency of $20 \mathrm{~Hz}$; a pulse amplitude of $\pm 50 \mathrm{mV}$ and a step potential of $1 \mathrm{mV}$. Other particular experimental conditions are indicated in the figures captions.

The composition of the real sample solutions were analyzed by the standardized ICP-AES method, using a SPECTRO CIROS CCD spectrometer (SPECTRO Analytical Instruments, Germany).

For the OPR measurements, a combined Pt sensor of SO50X type and a Consort C863 multi-channel-meter, both from Consort, Belgium, were used. The $\mathrm{pH}$ measurements were performed using a SenTix® 41 combined glass electrode connected to a $\mathrm{pH} /$ Cond 340i $\mathrm{pH}$-meter, both from WTW, Germany.

For the corrosion rate measurements, 2 rectangular samples $(20 \mathrm{~mm}$ * $20 \mathrm{~mm}{ }^{*} 2 \mathrm{~mm}$ ) from each pure metal were immersed in $100 \mathrm{~mL}$ of leaching solution containing $2 \mathrm{M} \mathrm{KBr}+0.5 \mathrm{M} \mathrm{HBr}+0.1 \mathrm{M}$ and stirred at $480 \mathrm{rpm}$. Periodically, the samples were extracted from the leaching solution, washed successively with $2 \mathrm{M} \mathrm{KBr}$, distilled water and acetone, dried and weighted. The values of corrosion rate were calculated reporting the weight loss to the sample surface, metal density and dissolution time. 
SENSORS ARRAY FOR MONITORING AND AUTOMATION OF THE ELECTROCHEMICAL RECOVERY OF METALS FROM WASTE PRINTED CIRCUIT BOARDS

\section{ACKNOWLEDGMENTS}

This work was supported by a grant of the Romanian Ministry of Research and Innovation, CCCDI - UEFISCDI, project number PN-III-P1-1.2-PCCDI-2017-0652 I 84PCCDI / 2018, within PNCDI III.

\section{REFERENCES}

1. Z. Liu, J. Tang, B.-Yi Li, Z. Wang, Journal of Cleaner Production, 2017, 167, 97.

2. F. Cucchiella, I. D’Adamo, S.C. Lenny Koh, P. Rosa, Renewable and Sustainable Energy Reviews, 2016, 64, 749.

3. S. Pinho, M. Ferreira, M. F. Almeida, Resources, Conservation and Recycling, 2018, $132,71$.

4. H. Wang, S. Zhang, B. Li, D. Pan, Y. Wu, T. Zuo, Resources, Conservation and Recycling, 2017, 126, 209.

5. H. Li, J. Eksteen, E. Oraby Resources, Conservation and Recycling, 2018, 139, 122.

6. C. Ning, C. S. K. Lin, D. C. W. Hui, G. McKay, Topics in Current Chemistry, 2017, 375(2), 1.

7. S. Fogarasi, F. Imre-Lucaci, A. Egedy, Á. Imre-Lucaci, P. Ilea, Waste Manage., 2015, 40, 136.

8. L. A. Diaz, T. E. Lister, Waste Management, 2018, 74, 384.

9. L. J. J. Janssen, L. Koene, Chemical Engineering Journal, 2002, 85, 137.

10. K. Juttner, U. Galla, H. Schmieder, Electrochimica Acta, 2000, 45, 2575.

11. S. A. Dorneanu, Studia UBB Chemia, 2017, 62(3), 177.

12. E. A. Stricker, K. W. Krueger, R. F. Savinell, J.S. Wainright, Journal of The Electrochemical Society, 2018, 165(9), A1797.

13. P. Vanysek, Electrochemical Series, in CRC Handbook of Chemistry and Physics (92th ed.), Boca Raton FL, CRC Press, 2011, pp. 5-80 - 5-89.

14. S. A. Dorneanu, A. A. Avram, A. H. Marincaş, N. Cotolan, T. Frenţiu, P. llea, Studia UBB Chemia, 2018, 63(4), 147.

15. ${ }^{* * *}$, Directive 2002/95/EC of the European Parliament and of the Council of 27 January 2003 on the restriction of the use of certain hazardous substances in electrical and electronic equipment, Official Journal L 037, 13/02/2003, pp. 0019 0023

16. Y. Liu, K. Jiang, S. Yang, Materials, 2019, 12, 603.

17. F. I. Danilov, V. S. Protsenko, E. A. Vasil'eva, O. S. Kabat, Transactions of the Institute of Metal Finishing, 2011, 89(3), 151. 
